\title{
ЭКОНОМИКА КИТАЯ: ДОЛГОВАЯ НАГРУЗКА И ТЕМПЫ ЭКОНОМИЧЕСКОГО РОСТА
}

\author{
(c) 2019 Сахаров Андрей Андреевич \\ ассистент Департамента финансовых рынков и банков \\ Финансовый университет при Правительства РФ, Россия, Москва \\ E-mail:85asah@gmail.com
}

В статье рассмотрена проблема поддержания темпов экономического роста в Китае в условиях необходимости сокращения долговой нагрузки, обоснована необходимость замещения непрозрачных схем финансирования муниципальных бюджжетов прозрачными, а также показано, что оптимальной может стать политика по сочетанию фискальных и монетарных стимулов в зависимости от фазы экономического цикла.

Ключевые слова: облигации, долговая нагрузка, государственный долг, экономический рост, Китай, фискальная политика, монетарная политика, фискальная дисциплина, экономический цикл.

Правительство Китая ожидает, что в 2019 году рост экономики будет на уровне 6-6.5\% [1]. При этом 2018 год оказался худшим для Китая за последние 28 лет: ВВП вырос «всего» на 6,6\%. В среднем же, экономика Китая за последжние 30 лет ежегодно росла на 9\%, в то время как среднемировой показатель оказался чуть меньше 3\% [2,3] (Диаграмма 1).

Основная сложность в обеспечении заявленного на 2019 год уровня роста заключается в том, что модель китайской экономики строится на чрезмерно высокой доле долгового финансирования. И в массовом сознании участников рынка развилось что-то вроде «долговой фобии», когда любое увеличение долга считается нежелатель- ным и потенциально опасным.

У правителсьтва Китая возникает дилемма: с одной стороны, необходимо поддерживать темпы роста на высоком уровне, а с другой, предотвратить дальнейшее нарастание долговой нагрузки. Однако снижение объемов кредитования неизбежно приведет к замедлению темпов экономического роста.

Для решения данной задачи правительство Китая в 2015 году провозгласило стимулирующую фискальную политику, которая предполагает усиление фискальной дисциплины и фокус на муниципальные облигации как основной источник финансирования бюджета органов местного самоуправления.

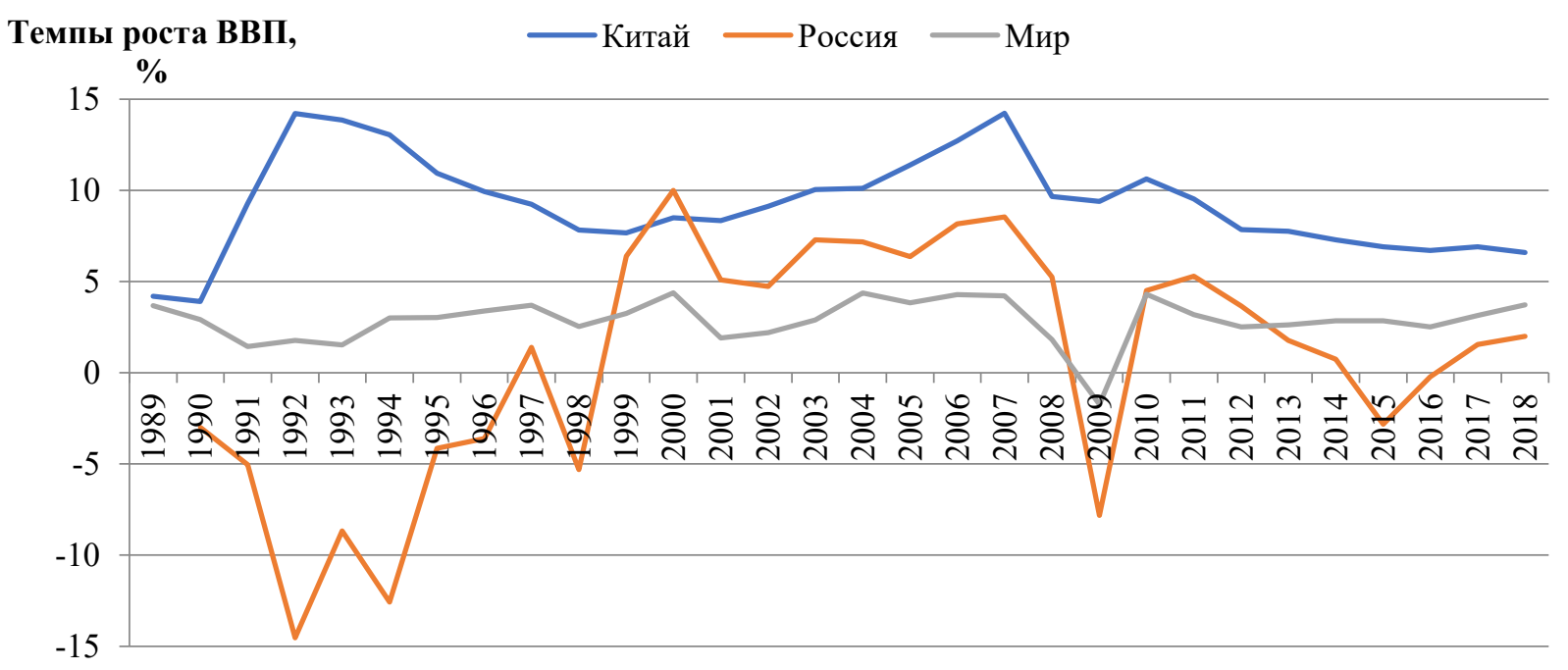

Диаграмма 1: Темпы роста ВВП некоторых стран, 2018 


\section{Усиление фискальной дисциплины}

Согласно официальным данным, по объему государственного долга Китай отнюнь не в лидерах. Однако во-первых, ввиду крупнейших объемов экономики, абсолютный размер китайского госдолга крайне существенный (более $\$ 13$ трлн.- здесь и далее приводится долларовый эквивалент китайских юаней, см. Диаграмму 2). Поэтому в случае реализации негативных сценариев последствия для мировой экономики могут оказаться гораздо серьезнее, чем например, в случае Греции или Италии. Во-вторых, приведенная выше цифра - официальная; неофициально же, по некоторым оценкам (в частности, the Institute of International Finance - IIF) [4], отношение китайского госдолга к ВВП может достигать 300\%. Достоверно подсчитать затруднительно, т.к. система крайне непрозрачна - отдельные органы власти и госучреждения выступают кредиторами друг друга, структура кредитования запутана.

Вот почему одной из основных задач в рамках стимулирующий политики стало усиление фискальной дисциплины. В этом отношении Правительство Китая видит своей задачей сформировать эффективные законные механизмы кредитования в форме муниципальных облигаций (“open the front door” - досл. «открыть парадную дверь») и одновременно перекрыть все остальные схемы привлечения финансирования, не отвечающие требованиям законности (“close the back door” - досл. «перекрыть черный ход») [4].
На практике задача принимает следующие формы: с 2015 года началось постепенное замещение «старого» долга органов местного самоуправления (выпущенного до 2015 года) на «новый» (в формате муниципальных облигаций). «Старый» долг, характеризующийся своей нерпозрачностью и наличием серых схем, после экспирации должен быть рефинансирован долгом «новым», прозрачным. При этом, именно муниципальные облигации должны стать той самой «парадной дверью» ("the front door").

\section{Муниципальные облигации}

Выпуск муниципальных облигаций может преследовать различные цели. Краткосрочные ноты, как правило, реализуются под обеспечение налоговых поступлений либо под будущие облигационные выпуски. Это позволяет органам местной власти покрывать временный или сезонный дефициты. Долгосрочные муниципальные облигации выпускаются под финансирование инфраструктурных проектов, например, строительство школ, мостов, улиц, аэропортов, а также для финансирования долгосрочного дефицита бюджета. Муниципальныен облигации нередко предполагают различные налоговые льготы [7].

Как говорилось выше, официально внутренний долг Китая по состоянию на конец 2018 превысил \$13 трлн., что соответствует половине ВВП. Из них 56\%, или $\$ 7.3$ трлн., приходится на облигации; остальные 44\% - кредиты и денежный рынок [6].

$$
\text { в \% от ВВП Федеральный долг } \quad \text { Муниципальный долг }
$$

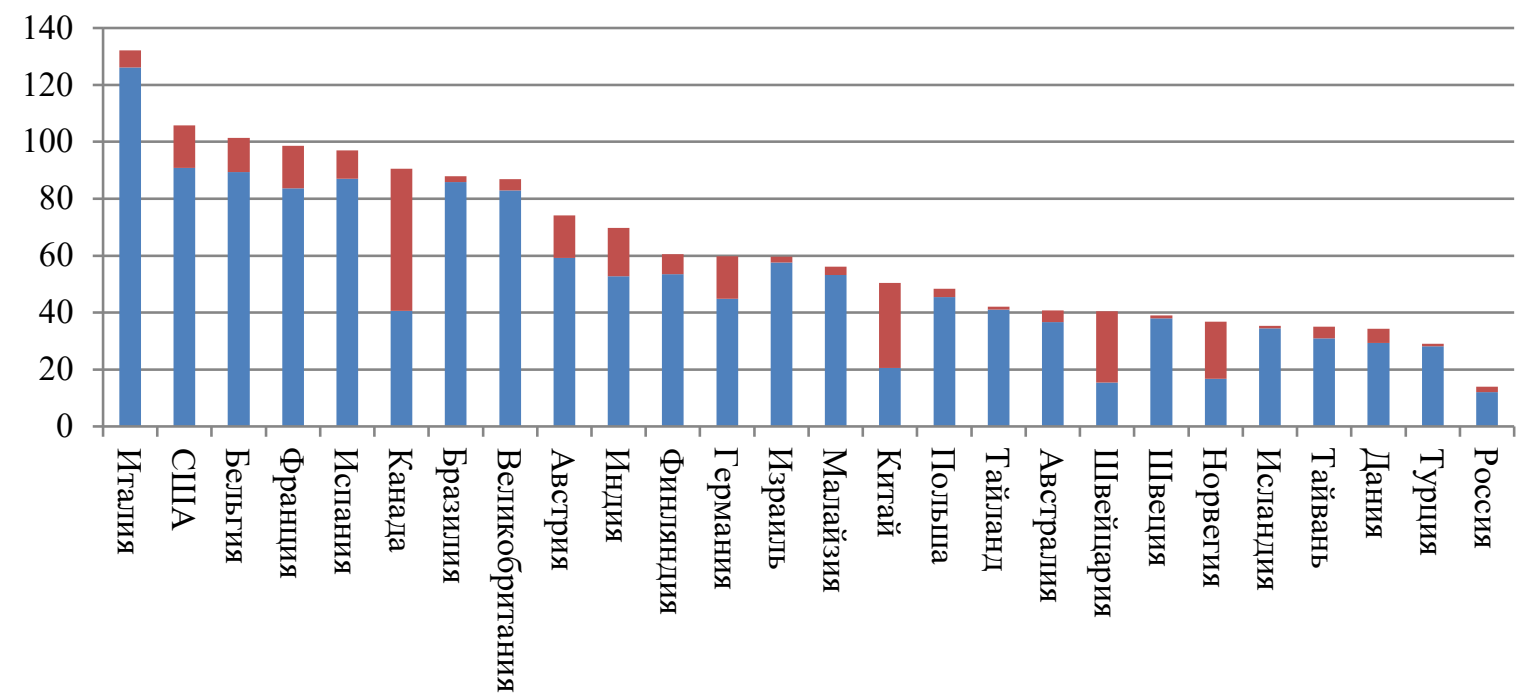

Диаграмма 2: Уровень госдолга отдельных стран, 2018 Источник: The World Bank 
K концу 2018 года объем муниципальных облигаций в обращении достиг \$2.6 трлн. (20\%) и, таким образом, превысил как объем облигаций федерального правительства, так и государственно-частных банков - по 18\%, или $\$ 2.35$, каждые [1].

Муниципальные облигации - явление для Китая относительно новое, были запущены в 2009 году. Выпуск существенно возрос с 2015 года, когда в рамках вновь провозглашенной стимулирующей политики правительство Китая увеличило на них квоты. Так, с 2015 года объем выпуска увеличился в 16 раз, в то время как выпуск облигаций федерального правительства и государственно-частных банков (ЭкспортноИмпортный Банк Китая и Сельскохозяйственный Банк Развития Китая) - всего в 1.3 раз [2].

Ожидается, что значение муниципальных облигаций в экономики Китая будет увеличиваться. Для воплощения в жизнь стимулирующей фискальной политики необходимо, чтобы объемы выпуска муниципальных облигаций отвечали запросам экономики, ведь если квоты не будут соответствовать спросу, экономический рост может замедлиться.

\section{Аспекты монетарной политики}

В части монетарной политики увеличение объемов выпуска муниципальных облигаций (или по-другому, фискальные стимулы) может привести к перетеканию финансовых ресурсов из частного сектора в государственный. Это потребует от китайских властей некторых мер монетарной политики для смягчения такого эффекта и максимизации роста экономики в целом.

Важно понимать, что эффект от монетарной политики может быть ограничен фазой экономического цикла (согласно принципу "Pushing on a string”, монетарная политика ассиметрична: проще ограничить рост, чем остановить спад). Кроме того, монетарная политика должна учитывать не только внутренние и внешние факторы, но и реальные и финансовые, хотя макропруденциальная политика способна до определенной степени сбалансировать влияние этих факторов [5].

Наиболее практичным подходом представляется следование стимулирующей фискальной политике в периоды замедления экономического роста, как в настоящее время, и фискальной консолидации в периоды, когда экономика растет в соответствии со своим потенциалом.

В заключение отметим, что решительность китайских властей укрепить финансовую дисциплину с 2015 года заметно возросла, а толератность к дальнейшему накоплению серого долга снизилась. Правительство не готово жертвовать финансовой стабильностью ради стимулирования экономичсекого рост. По нашему мнению, это крайне положительный сигнал для участников рынка, однако непобходимо проследить, насколько эффективно завленное получится воплотить на практике.

\section{Библиографический список}

1. Международный валютный фонд (IMF): https://www.imf.org/

2. Всемирный банк (The World Bank): http://www.worldbank.org/

3. Народный банк Китая (РВоC): http://www.boc.cn/en/

4. Fabozzi F.J. // Band Markets, Analysis and Strategies (7th edition). Pearson International Edition, 2010. - 778 p.

5. Li Z., Tang M., Song Y., Wei M., Tilton A. China's blossoming local government market: Macro implications amid cyclical weakness and "debt phobia" // Goldman Sachs Investment Research:, 22 Feb 2019

6. Li Z., Tang M., Song Y., Wei M., Tilton A. China’s Government Bond Market: How to Surge in Municipal Bonds is Reshaping a Bank-dominated Market // Goldman Sachs Investment Research, 3 March 2019

7. Mourdoukoutas P. Debt, Not Trade Was, Is China’s Biggest Problem // Forbes, 24 Nov 2018 